\title{
THE MANAGEMENT AND PREVENTION OF POST.PARTUM HAEMORRHAGE IN A CLINIC
}

\author{
J.V. Larsen M.R.C.O.G., \\ Department of Obstetrics and Gynaecology, \\ University of Natal, King Edward VIII Hospital, Durban.
}

\section{OPSOMMING}

Postpartum-bloeding wat gedefinieer word as oormatige bloedverlies vanaf die geslagskanaal na die geboorte van die fetus word in besonderheid beskryf, die behartiging en voorkoming daarvan uiteengesit en die nodige optrede van die vroedvrou duidelik verklaar.

INTRODUCTION

DOST-PARTUM haemorrhage is best defined as excessive blood loss from the genital tract following the birth of the fetus. For statistical purposes, the definition of excessive blood loss is $600 \mathrm{ml}$ or more. Traditionally, post-partum haemorrhage is divided into primary PPH which is bleeding ocurring within 24 hours of delivery, and secondary PPH which is bleeding occurring after that time.

\section{Classification of Post-Partum Haemorrhage According to Cause}

In considering the management of post-partum haemorrhage, it is much more valuable to classify excessive blood loss according to its cause.

Hypotonic post-partum haemorrhage occurs because the uterus fails to undergo adequate contraction and retraction following the delivery of the baby. This type of post-partum haemorrhage can be torrential and terrifying and usually occurs within half an hour of delivery.

Traumatic post-partum haemorrhage occurs as a result of trauma to the genital tract at any level from the uterus to the vulva. The amount and duration of bleeding will depend upon such factors as what structure has been damaged, and whether there is any supervening sepsis.

Haemorrhage caused by retained products of conception can occur immediately as in the case of post-abortal bleeding, or may be delayed as long as 10 days as in the case of a retained placental cotyledon.

Bleeding associated with coagulation defects almost always occurs within the first half hour of delivery.

Because a fully developed post-partum haemorrhage can be such a serious and terrifying condition, its prevention under each of these headings is discussed before the management of the bleeding patient in a clinic.

\section{HYPOTONIC POST-PARTUM HAEMORRHAGE}

Hypotonic post-partum haemorrhage should be expected in any patient who is suffering from hypotonic uterine inertia. This pattern of labour can occur in any patient during labour, although it is most commonly found in grande multiparae, patients with multiple pregnancy, and patients with hydramnios. It is characterised by weak contractions occurring at long intervals during the active phase of labour, i.e. after $4 \mathrm{~cm}$ dilatation of the cervix. Strictly speaking, post-partum haemorrhage associated with placenta praevia is due to hypotonic post-partum haemorrhage because the lower uterine segment in which the abnormally situated placenta has embedded, does not normally undergo good contraction and retraction. Occasionally the Couvelaire uterus of an accidental haemorrhage will fail to contract properly in the third stage because of damage done to its fibres by dissecting blood and kinin release.

Prevention of hypotonic post-partum haemorrhage at the clinic level can therefore largely be achieved by selecting all patients with multiple pregnancy, hydramnios, and ante-partum haemorrhage for hospital delivery, and by admitting them to the waiting mothers' area before the onset of labour. In a rural situation with poor communications, grande multiparae should be added to this list.

Both at the base hospital and at the clinic, hypotonic patterns of labour should always be corrected before the 
second stage commences. This is best done in the clinic by rupturing the membranes provided the cervix is more than $4 \mathrm{~cm}$ dilated and having the patient walk about in the labour ward. The patient should then be re-assessed two hours later and, if the pattern of labour has not been corrected, she should be transferred to the hospital for an oxytocic infusion. If the patient is already more than $7 \mathrm{~cm}$ dilated when the diagnosis of hypotonic inertia is made, she should be transferred because an oxytocic infusion should be commenced at the time of artificial rupture of membranes. In the case of twin labour, it is always valuable to have an intravenous infusion running before the onset of second stage. Weak contractions which persist longer than 10 minutes after the birth of the first twin should then usually be corrected with an oxytocic infusion before the second twin is delivered, provided the lie is longitudinal, and presentation not a brow or face.

Some older midwives would add a large enema to this sequence of management, but this is of doubtful value.

In order to prevent hypotonic post-partum haemorrhage occuring in patients in whom the diagnosis of hypotonic inertia has been missed, it is recommended that the third stage of labour should always be managed by giving Syntometrine (ergometrine tartrate $0,5 \mathrm{mg}$, oxytocin 5 i.u. : Sandoz) with the birth of the anterior shoulder and following this with Brandt-Andrew's manoeuvre. If the patient is seriously hypertensive and the Ergometrine part of Syntometrine is contraindicated, an alternative regime is to give 10 units of oxytocin intramuscularly followed by a 20 units per litre oxytocic infusion.

\section{TRAUMATIC POST-PARTUM HAEMORRHAGE}

Traumatic post-partum haemorrhage occurs most commonly in patients requiring operative vaginal delivery, in those unco-operative patients who provoke a precipitate delivery by pushing uncontrollably against an incompletely dilated cervix, in patients with cephalopelvic disproportion (be it surmountable or insurmountable), and in patients who undergo criminal abortion.

Post-partum haemorrhage following operative vaginal delivery is usually due to lacerations of the vulva and vagina. It is important to point out that lacerations near the clitoris may bleed very profusely and may only be seen if specifically looked for by separating the labia minora. Similarly, longitudinal lacerations closely related to the labia minora are easily missed unless the labia are carefully separated and inspected. Most of these lacerations on the anterior and lateral vaginal walls can be prevented by the use of well-timed adequate episiotomies.

The unco-operative patient who pushes her baby through her cervix and perineum, can sustain multiple lacerations of this sort, and also-tear her cervix. Cervical lacerations can of course also occur when the vacuum extractor is employed before full dilatation. Lacerations of the vaginal fornices and of the cervix are frequently found after attempts at criminal abortion.

When there is cephalopelvic disproportion, lacerations of the lower genital tract are common when the disproportion is worst at the mid-cavity and outlet of the pelvis. Trauma to, or rupture of the uterus occurs when there is serious disproportion at any level in the pelvis, but most commonly at the pelvic brim. This is particularly so if the uterus has been damaged at a previous Caesarean section, or by a previous long and difficult labour, or perforated accidentally at the time of dilatation and curettage or evacuation.

Traumatic post-partum haemorrhage at the clinic level can largely be prevented by the selection of all patients who have small pelves, very big babies, or a scarred uterus for whatever reason, for hospital delivery. Such patients in a rural area would ideally be admitted to a waiting mothers' area well before the onset of labour, i.e. usually at 37 weeks gestation. Adequate sedation in labour (and this means clinic midwives must be permitted to give Pethidine for pain relief) and adequate psychological preparation of the patient in the antenatal clinic in the form of health education and possibly relaxation exercises, should eliminate postpartum haemorrhage due to uncontrolled delivery.

It is of course true that even when selection of patients for clinic delivery is excellent, some will still develop cephalopelvic disproportion in labour at the clinic. The disciplined use of the Philpott Labour Graph enabling timeous transfer of all patients making inadequate progress should lead to early recognition and hospital management of all such patients ${ }^{1}$.

At the base hospital level, it is of course important to the prevention of traumatic post-partum haemorrhage that all staff undertaking operative delivery have an adequate level of technical skill.

\section{RETAINED PRODUCTS OF CONCEPTION}

This condition can be expected in all patients in whom separation and evacuation of the placenta is incomplete. It is therefore very common in patients who abort under 20 weeks gestation, and possibly more common in patients who have a scarred uterus because the decidua overlying the scar is frequently abnormally thin.

As a cause of post-partum haemorrhage, it is best detected by disciplined examination of the placenta and membranes after delivery. Any patient in whom the placenta appears incomplete should be referred from the clinic to the base hospital where digital exploration of the uterus under general anaesthesia will confirm the diagnosis. Evacuation of the uterus can then be performed. Retained products of conception not dealt with in this way will usually declare themselves later at the time of a secondary post-partum haemorrhage or of 
puerperal sepsis, when the presence of subinvolution of the uterus and an open cervix will suggest the correct diagnosis. Prevention of secondary post-partum haemorrhage due to retained products of conception therefore demands careful examination of the placenta in all patients and the examination of every patient on the third and fifth post-partum days in order to detect pyrexia and subinvolution.

Every midwife remembers from her training that prevention of primary post-partum haemorrhage due to a partially separated retained placenta involves correct management of the third stage of labour, and the avoidance of the habit of fiddling with the fundus. Active management involving the giving of Syntometrine with the birth of the anterior shoulder followed by Brandt-Andrew's manoeuvre removes the temptation to fiddle.

\section{COAGULATION DEFECTS}

Post-partum haemorrhage due to defects in the mechanisms of coagulation can occur in many patients who suffer a large accidental haemorrhage ${ }^{2}$, and in those pregnancies complicated by intra-uterine death or missed second trimester abortion in whom the fetus is retained for more than three weeks ${ }^{3}$.

In these two groups of patients, the mechanism of the defect is that of a disseminated intravascular coagulopathy due to the release into the general circulation of blood and tissue thromboplastins. Haemorrhage due to inter-current blood dyscrasias such as idiopathic thrombocytopaenia and acute leukaemia are very rare in pregnancy.

Early and aggressive management of accidental haemorrhage, aiming at emptying the uterus within 8 to 12 hours of the onset of bleeding, undoubtedly reduces the incidence of disseminated intravascular coagulopathy in this condition. Health education at a clinic must always therefore include the advice that the patient should return to the clinic immediately should she develop vaginal bleeding or unexplained abdominal pain. Localised uterine tenderness of recent onset with or without vaginal bleeding should be an indication for urgent transfer of the patient by ambulance from the clinic to the base hospital. There, free use should be made of Caesarean section if the baby is still alive, or if clinical signs suggest that the prospect of vaginal delivery within this time interval is remote.

A coagulation defect can usually be prevented in the case of intra-uterine death and missed abortion if the uterus is emptied within 3 to 4 weeks of the death of the baby. Every patient suspected of having an intra-uterine death or missed abortion should therefore be referred to the base hospital for assessment immediately.

When patients present late in the course of their disease, the diagnosis of disseminated intravascular coagulopathy can be made by doing a crude clotting time. The defect should always be corrected if possible before the uterus is emptied.
A summary of the important steps in preventing the occurrence of post-partum haemorrhage at the clinic is set out below.

\section{PREVENTION OF POST-PARTUM HAEMORRHAGE IN THE CLINIC}

A. Hypotonic post-partum haemorrhage: Prevent by: Correct hypoţonic patterns of labour before second stage:

? Enema?

Artificial rupture of membranes

Up and about

Oxytocic infusion

Routine Syntometine with anterior shoulder combined with Brandt-Andrew's manoeuvre.

B. Traumatic post-partum haemorrhage: Prevent by: Adequate psychological preparation in antenatal clinic

Adequate sedation

Early recognition and management of cephalopelvic disproportion

Good technical skill.

C. Retained products of conception: Detect by: Disciplined examination of placenta and membranes

Subinvolution with an open cervix

Prevent by early evacuation of the uterus.

\section{Coagulation defects: Prevent by:}

Aggressive management of accidental haemorrhage

Empty uterus in patients with I.U.D. or missed abortion under 4 weeks.

\section{MANAGEMENT OF PRIMARY POST-PARTUM HAEMORRHAGE IN A CLINIC SITUATION}

In spite of all her attempts to prevent the condition occurring in her clinic, the midwife will still occasionally be faced with a post-partum haemorrhage when she is far from the assistance of a medical officer. The cause of such a post-partum haemorrhage is seldom immediately apparent, and the following sequence of management is therefore suggested:

(1) React to excessive bleeding before the statutory 600 $\mathrm{ml}$ has been lost.

(2) Repeat Syntometrine intramuscularly. If Ergometrine is contraindicated because of hypertension, start an intravenous infusion of 20 units of oxytocin per litre at 40 drops per minute.

(3) While this is being done review the nature of the labour. If contractions were weak at the time of full dilatation, bleeding is probably due to a hypotonic uterus. If the baby's head was excessively moulded the bleeding is almost certainly traumatic in origin. While the nature of the labour is being reviewed, re-examine the placenta to ensure that a cotyledon is not retained. 
(4) If the placenta is still retained when bleeding begins, remove it by repeated Brandt-Andrew's manoeuvres. If the placenta does not come or the cord breaks off, do a gentle vaginal examination. If the placenta can be felt protruding through the cervix it should be grasped with the fingers and steadily withdrawn from the uterus which is supported through the abdominal wall with the left hand. Only when haemorrhage is severe should a midwife in a peripheral clinic undertake a formal manual removal of a placenta that is still wholly in the uterus. Control of haemorrhage can be achieved if the placenta cannot be removed by bimanual compression of the uterus.

(5) When the placenta has been removed, rub up the uterus to achieve a sustained contraction. Should bleeding persist, place the patient in lithotomy position and with the aid of a good light examine the vulva and vagina for lacerations which are bleeding. Pressure upon each bleeding point will establish whether this is the chief source of haemorrhage.

(6) Should a visible bleeding laceration prove to be the chief source of haemorrhage, it should be sutured immediately under local anaesthesia.

(7) If there is no local source of bleeding on the vulva or vagina, and the review of the pattern of labour suggests that it was hypotonic, persistent bleeding may be due to an accumulation of blood clot inside the uterus. This can be simply removed by doing a gentle vaginal examination and passing two fingers through into the cervix into the uterus. If the fundus of the uterus is then controlled with the left hand and brought down on to these two fingers, clots within the uterus can be gently and effectively scraped out. Bleeding will then cease.

(8) Should all these measures fail, and bleeding persist, it is probably due to a laceration of the cervix or upper vagina, a rupture of the uterus, or a coagulation defect. All these causes of post-partum haemorrhage can be effectively controlled by bimanual compression of the uterus. This is achieved by placing a rolled-up sterile sanitary pad inside the vagina and following it with the gloved fist of the right hand. The left hand is then employed to apply pressure to the fundus of the uterus and between both hands effective control of haemorrhage can be achieved.
(9) At this point it is valuable to start an intravenous infusion of 1 litre of Ringer's Lactate with 20 units of oxytocin. Provided the midwife has acted rapidly in accordance with this sequence, the patient should not be shocked. If she has become shocked, however, the drip should always be commenced as soon as this is noticed, preferably by a colleague, while bi-manual compression of the uterus is commenced in order to prevent further blood loss. A shocked patient should always receive at least 1 litre of Ringer's Lactate fast before she is moved.

(10) The patient should then be transferred as speedily as possible to hospital. When the ambulance is ready at the clinic, the midwife should remove her fist and the pad from the vagina and observe whether bleeding has ceased. If heavy bleeding recommences, bi-manual compression of the uterus should be continued in the ambulance and into theatre at the base hospital, where the doctor in charge can perform an examination under anaesthesia and plan definitive management.

\section{MANAGEMENT OF A SECONDARY POST- \\ PARTUM HAEMORRHAGE IN A CLINIC}

Post-partum haemorrhage occurring later than 24 hours after delivery is nearly always due to retained products of conception, sepsis or trauma. None of these conditions can be satisfactorily managed in a clinic. The clinic midwife's duty to these patients is therefore fairly simple: to resuscitate the patient with intravenous fluids if she is shocked and to move the patient as rapidly as is necessary to hospital. Only in the case of late bleeding from an unrecognised rupture of the cervix and uterus will bleeding be so heavy that it must be stopped in order to improve the patient's condition during transfer. Bi-manual compression of the uterus can be employed here as well.

It is relevant to point out that a light bleed may precede heavy vaginal bleeding from separation of a retained placental cotyledon. Therefore recurrence of moderate vaginal bleeding after the fourth or fifth day in the puerperium deserves investigation at the base hospital.

\footnotetext{
REFERENCES

1. Philpott, R.H. (1978) in Philpott, Sapire and Axton (Ed) "Obstetrics, Family Planning nd Paedlatrics". Natal University Press, page 91.

2. Rizza, C.R. (1970) in Philip, Barnes and Newion (Ed.) "Scientific Foundations of Obste1rics and Gyngecalngy". Heinemann, page 323

3. Donald, I. (1969): "Practical Ohsietric Prahlemg". Lloyd-Luke, page 411
} 